\title{
Advanced Age as a Predictor of Survival and Weaning in Venoarterial Extracorporeal Oxygenation: A Retrospective Observational Study
}

\author{
WooSurng Lee, ${ }^{1}$ YoHan Kim, ${ }^{1}$ HyunHee Choi, ${ }^{2}$ HyoungSoo Kim, ${ }^{3}$ SunHee Lee, ${ }^{3}$ \\ HeeSung Lee, ${ }^{4}$ HyunKeun Chee, ${ }^{5}$ JunSeok Kim, ${ }^{5}$ JaeJoon Hwang, ${ }^{5}$ SongAm Lee, ${ }^{5}$ \\ YongHun Kim, ${ }^{6}$ SeongJoon Cho, ${ }^{7}$ SeMin Ryu, ${ }^{7}$ and SungMin Park ${ }^{7}$ \\ ${ }^{1}$ Department of Thoracic and Cardiovascular Surgery, School of Medicine, Konkuk University Chungju Hospital, \\ Konkuk University, Chungju-si, Chungbuk, Republic of Korea \\ ${ }^{2}$ Department of Internal Medicine and Division of Cardiology, College of Medicine, Hallym University Chuncheon \\ Sacred Heart Hospital, Hallym University, Chuncheon-si, Gangwon-do, Republic of Korea \\ ${ }^{3}$ Department of Thoracic and Cardiovascular Surgery, College of Medicine, Hallym University Sacred Heart Hospital, \\ Hallym University, Gyeonggi-do, Republic of Korea \\ ${ }^{4}$ Department of Thoracic and Cardiovascular Surgery, College of Medicine, Hallym University Dongtan Sacred Heart Hospital, \\ Hallym University, Gyeonggi-do, Republic of Korea \\ ${ }^{5}$ Department of Thoracic and Cardiovascular Surgery, School of Medicine, Konkuk University Seoul Hospital, \\ Konkuk University, Seoul, Republic of Korea \\ ${ }^{6}$ Department of Surgery, School of Medicine, Konkuk University Chungju Hospital, Konkuk University, \\ Chungju-si, Chungbuk, Republic of Korea \\ ${ }^{7}$ Department of Thoracic and Cardiovascular Surgery, School of Medicine, Kangwon National University, \\ Chuncheon-si, Gangwon-do, Republic of Korea
}

Correspondence should be addressed to HeeSung Lee; timesgobytimesgoby@gmail.com

Received 8 November 2016; Revised 16 January 2017; Accepted 7 March 2017; Published 6 April 2017

Academic Editor: Giovanni Mariscalco

Copyright (C) 2017 WooSurng Lee et al. This is an open access article distributed under the Creative Commons Attribution License, which permits unrestricted use, distribution, and reproduction in any medium, provided the original work is properly cited.

Background. In most reports on ECMO treatment, advanced age is classified as a contraindication to VA ECMO. We attempted to investigate whether advanced age would be a main risk factor deciding VA ECMO application and performing VA ECMO support. We determined whether advanced age should be regarded as an absolute or relative contraindication to VA ECMO and could affect weaning and survival rates of VA ECMO patients. Methods. VA ECMO was performed on 135 adult patients with primary cardiogenic shock between January 2010 and December 2014. Successful weaning was defined as weaning from ECMO followed by survival for more than 48 hours. Results. Among the 135 patients, 35 survived and were discharged uneventfully, and the remaining 100 did not survive. There were significant differences in survival between age groups, and older age showed a lower survival rate with statistical significance $(P=.01)$. By multivariate logistic regression analysis, age was not significantly associated with inhospital mortality $(P=.83)$ and was not significantly associated with VA ECMO weaning $(P=.11)$. Conclusions. Advanced age is an undeniable risk factor for VA ECMO; however, patients of advanced age should not be excluded from the chance of recovery after VA ECMO treatment.

\section{Introduction}

Extracorporeal life support (ECLS) is a general terminology used to describe support of cardiac or pulmonary function with a mechanical device. Initial experience with extracorporeal membrane oxygenation (ECMO) was employed for acute respiratory distress syndrome, with the early experience with ECMO predominantly reported in neonatal and 
pediatric cohorts [1-3]. ECMO has remarkably progressed over the past several decades and has been accepted as an invaluable tool to treat children and adults with severe cardiac and/or pulmonary dysfunction refractory to conventional management [4-12]. This outstanding achievement and an immense increase in the number of patients who were treated with ECMO, as well as expansion of ECMO indications, raise ethical issues and dilemmas on which patients should be treated with ECMO and when ECMO support should be stopped [13]. The ELSO described that advanced age is an absolute or relative contraindication to ECMO in adult cardiac failure cases and that although advanced age is no specific contraindication to ECMO, the risk of mortality increases with age in adult respiratory failure cases [14, 15]. Physicians face a therapeutic dilemma as to whether ECMO support should be initiated to treat patients of advanced age with severe cardiac and pulmonary dysfunction refractory to conventional management. Because ECMO supplies supportive therapy rather than disease-modifying treatment, the best treatment outcome could be obtained when appropriate patients, relevant ECMO types, and proper configurations are chosen [16, 17]. Established ELSO indications in adults show that advanced age belongs to an absolute or relative contraindication to venoarterial (VA) ECMO. In most reports on ECMO treatment, advanced age is classified as an absolute contraindication to VA ECMO, so that VA ECMO is not recommended for patients of advanced age. Unfortunately, since there are no definite age criteria for VA ECMO, it is essential to make a decision as to whether age is actually a primary risk of VA ECMO and what would be the optimal age for VA ECMO. We attempted to investigate whether advanced age would be a main risk factor for deciding VA ECMO application and performing VA ECMO support. Additionally, we attempted to determine whether advanced age should be regarded as an absolute or relative contraindication to VA ECMO and could affect weaning and survival rates of VA ECMO patients.

\section{Subjects and Methods}

2.1. Study Patients. The ECMO support program was first initiated at a single medical center in January 2006, and VA ECMO was performed on 135 adult patients with primary cardiogenic shock between January 2010 and December 2014. All the patients were aged $\geq 18$ years. They received VA ECMO at a single medical center by a single ECMO team directed mainly by cardiothoracic surgeons, which was performed for refractory cardiogenic shock and various medical conditions (Table 1). To avoid selection bias, this study excluded patients with respiratory failure undergoing VV ECMO. ELSO indications for VA ECMO in adults were applied; however, advanced age was not considered an absolute or relative contraindication. Successful weaning was defined as weaning from ECMO followed by survival for more than 48 hours. Survival was defined as weaning from ECMO and improvement in an underlying clinical condition followed by discharge from the hospital. This study was approved by the Institutional Review Board (2013-105), and informed consent was waived due to its retrospective study design.

2.2. Data Collection. We retrospectively analyzed all patients who underwent VA ECMO support. They were registered in a unique ECMO register form, and additional data were obtained from the medical records of 135 patients. Pre-ECMO characteristics, including age, sex, body mass index (BMI), medical history, and underlying disease, as well as pre-ECMO information about cardiac arrest, including the location of arrest, extracorporeal cardiopulmonary resuscitation (ECPR) time, and complications associated with cardiopulmonary resuscitation (CPR) or ECMO CPR, were obtained. Additionally, pre-ECMO data-including laboratory findings, sepsis-related organ failure assessment (SOFA) score, preECMO simplified acute physiology score II (SAPS II), doorto-ECMO time, and ECMO duration-and post-ECMO data-ECMO mode, anticoagulation, duration, continuous renal replacement therapy, transfusion, and length of hospital stay-were retrospectively assessed. In cases of cardiac arrest, heart rate and Glasgow Coma Scale score were calculated at the lowest value. If a patient died within 24 hours, the variable urine output was estimated by multiplying average hourly urine output (total urine output divided by total time) by $24[18,19]$. Acute kidney injury was defined according to the acute kidney injury network (AKIN) and the risk, injury, failure, loss of kidney function, and end-stage kidney disease (RIFLE) classification system which comprises individual serum creatinine $(\mathrm{Cr})$ levels and urine output $[20,21]$.

2.3. Indications. The application of ECMO support is usually considered in critically ill patients and indicated when the mortality exceeds $80 \%$ without ECMO support [22]. The ELSO recommended that indications for ECLS must be limited to severe acute cardiac or respiratory failure with high mortality risk despite optimal conventional therapy. The application of ECLS is first considered at $50 \%$ mortality risk, and then it is indicated in most clinical conditions at $80 \%$ mortality risk. Disease severity and mortality risk were measured as precisely as possible using measurements for appropriate age and organ failure [23]. Main indications for VA ECMO were as follows: (1) refractory cardiogenic shock with a systolic blood pressure of $<80 \mathrm{~mm} \mathrm{Hg}$ despite appropriate conventional treatment, or cardiogenic shock combined with septic or neurogenic shock; (2) cardiac arrest that did not respond to returned spontaneous circulation within 10 minutes of CPR; and (3) recurrent cardiac arrest within 20 minutes after return of spontaneous circulation in spite of optimal CPR. One of the most common contraindications to VA ECMO is cerebral hemorrhage, because it requires anticoagulation and may aggravate cerebral hemorrhage. Another contraindication to VA ECMO is severe immunosuppression due to systemic inflammation, unwitnessed cardiac arrest, terminal-stage conditions, including terminal malignancy, or low possibility of full recovery [22]. VA ECMO is most frequently adopted in cardiogenic shock caused by a variety of etiologies, such as postmyocardial infarction, fulminant myocarditis, peripartum cardiomyopathy, cardiac depression 
TABLE 1: Demographic and clinical characteristics of the study patients according to in-hospital mortality and ECMO weaning.

\begin{tabular}{|c|c|c|c|c|c|c|c|}
\hline & \multirow[b]{2}{*}{$\begin{array}{l}\text { All patients } \\
(n=135)\end{array}$} & \multicolumn{3}{|c|}{ Survivor or nonsurvivor } & \multicolumn{3}{|c|}{ Successful or failed weaning from ECMO } \\
\hline & & $\begin{array}{l}\text { Survivors } \\
(n=35)\end{array}$ & $\begin{array}{l}\text { Nonsurvivors } \\
\quad(n=100)\end{array}$ & $P$ & $\begin{array}{l}\text { Successful weaning } \\
\qquad(n=53)\end{array}$ & $\begin{array}{l}\text { Failed weaning } \\
\qquad(n=82)\end{array}$ & $P$ \\
\hline Age (years) & $59.44 \pm 16.55$ & $51.91 \pm 17.63$ & $62.08 \pm 15.40$ & .002 & $55.43 \pm 18.67$ & $62.03 \pm 14.57$ & .02 \\
\hline Gender $(\mathrm{M} / \mathrm{F})$ & $94 / 41$ & $27 / 8$ & $67 / 35$ & .36 & $38 / 15$ & $56 / 26$ & .82 \\
\hline Height $(\mathrm{cm})$ & $164.10 \pm 8.73$ & $166.68 \pm 7.60$ & $163.20 \pm 8.95$ & .04 & $165.02 \pm 7.98$ & $163.51 \pm 9.18$ & .33 \\
\hline Body weight (kg) & $66.46 \pm 11.07$ & $68.62 \pm 11.41$ & $65.70 \pm 10.90$ & .18 & $67.75 \pm 10.88$ & $65.62 \pm 11.17$ & .28 \\
\hline Body mass index $\left(\mathrm{kg} / \mathrm{m}^{2}\right)$ & $24.61 \pm 3.36$ & $24.69 \pm 3.93$ & $24.58 \pm 3.16$ & .87 & $24.85 \pm 3.52$ & $24.46 \pm 3.26$ & .51 \\
\hline Body mass index (BMI) & & & & .38 & & & .90 \\
\hline Normal $(18.5 \leq \mathrm{BMI} \leq 22.9)$ & $50(37.0 \%)$ & 15 & 35 & & 18 & 32 & \\
\hline Overweight $(23 \leq \mathrm{BMI} \leq 24.9)$ & $34(25.2 \%)$ & 7 & 27 & & 14 & 20 & \\
\hline Obese $(25 \leq \mathrm{BMI} \leq 29.9)$ & $45(33.3 \%)$ & 10 & 35 & & 18 & 27 & \\
\hline Highly obese $(\mathrm{BMI} \geq 30)$ & $6(4.4 \%)$ & 3 & 3 & & 3 & 3 & \\
\hline ECMO type & & & & .18 & & & .43 \\
\hline VA ECMO & $129(95.6 \%)$ & 32 & 97 & & 50 & 79 & \\
\hline VV-VA ECMO & $3(2.2 \%)$ & 2 & 1 & & 2 & 1 & \\
\hline VA-VV ECMO & $1(0.7 \%)$ & 0 & 1 & & 0 & 1 & \\
\hline VAV ECMO & $1(0.7 \%)$ & 1 & 0 & & 1 & 0 & \\
\hline VA-VAV ECMO & $1(0.7 \%)$ & 0 & 1 & & 0 & 1 & \\
\hline Anticoagulation & & & & .31 & & & .13 \\
\hline With heparin & $55(40.7 \%)$ & 14 & 41 & & 23 & 32 & \\
\hline With nafamostat & $74(54.8 \%)$ & 21 & 53 & & 30 & 44 & \\
\hline No anticoagulation & $6(4.4 \%)$ & 0 & 6 & & 0 & 6 & \\
\hline Primary origin & & & & .27 & & & .56 \\
\hline Cardiac origin & $105(77.8 \%)$ & 25 & 80 & & 42 & 63 & \\
\hline Respiratory origin & $1(0.7 \%)$ & 1 & 0 & & 1 & 0 & \\
\hline Sepsis origin & $27(20.0 \%)$ & 8 & 19 & & 9 & 18 & \\
\hline Trauma origin & $2(1.5 \%)$ & 1 & 1 & & 1 & 1 & \\
\hline Admission route & & & & .49 & & & .36 \\
\hline Via ER & $84(62.2 \%)$ & 24 & 60 & & 36 & 48 & \\
\hline Via ward & $51(37.8 \%)$ & 11 & 40 & & 17 & 34 & \\
\hline Arrest occurrence & & & & $<.001$ & & & .001 \\
\hline Arrest & $101(74.8 \%)$ & 16 & 85 & & 31 & 70 & \\
\hline No arrest & $34(25.2 \%)$ & 19 & 15 & & 22 & 12 & \\
\hline Arrest place & & & & $<.001$ & & & .001 \\
\hline Out-hospital arrest & $34(25.2 \%)$ & 10 & 24 & & 13 & 21 & \\
\hline In-hospital arrest & $67(49.6 \%)$ & 6 & 61 & & 18 & 49 & \\
\hline No arrest & $34(25.2 \%)$ & 19 & 15 & & 22 & 12 & \\
\hline $\mathrm{CPR}$ & & & & $<.001$ & & & .002 \\
\hline Yes & $102(75.6 \%)$ & 17 & 85 & & 32 & 70 & \\
\hline No & $33(24.4 \%)$ & 18 & 15 & & 21 & 12 & \\
\hline CPR time (min) & $54.69 \pm 39.55$ & $34.41 \pm 21.15$ & $58.75 \pm 41.18$ & .02 & $45.50 \pm 42.00$ & $58.90 \pm 37.95$ & .11 \\
\hline ECPR & & & & $<.001$ & & & .005 \\
\hline Yes & $87(64.4 \%)$ & 12 & 75 & & 26 & 61 & \\
\hline No & $48(35.6 \%)$ & 23 & 25 & & 27 & 21 & \\
\hline Operation & & & & .38 & & & .48 \\
\hline No OP & $122(90.4 \%)$ & 30 & 92 & & 47 & 75 & \\
\hline ECMO after OP & $4(3.0 \%)$ & 2 & 2 & & 2 & 2 & \\
\hline
\end{tabular}


TABLE 1: Continued.

\begin{tabular}{|c|c|c|c|c|c|c|c|}
\hline & \multirow[b]{2}{*}{$\begin{array}{l}\text { All patients } \\
(n=135)\end{array}$} & \multicolumn{3}{|c|}{ Survivor or nonsurvivor } & \multicolumn{3}{|c|}{ Successful or failed weaning from ECMO } \\
\hline & & $\begin{array}{l}\text { Survivors } \\
(n=35)\end{array}$ & $\begin{array}{l}\text { Nonsurvivors } \\
\qquad(n=100)\end{array}$ & $P$ & $\begin{array}{l}\text { Successful weaning } \\
\qquad(n=53)\end{array}$ & $\begin{array}{l}\text { Failed weaning } \\
\qquad(n=82)\end{array}$ & $P$ \\
\hline OP with ECMO & $2(1.5 \%)$ & 0 & 2 & & 0 & 2 & \\
\hline OP after ECMO & $7(5.2 \%)$ & 3 & 4 & & 4 & 3 & \\
\hline HD (days) & $17.0 \pm 22.66$ & $43.4 \pm 28.25$ & $7.8 \pm 9.42$ & $<.001$ & $33.4 \pm 27.41$ & $6.4 \pm 8.70$ & $<.001$ \\
\hline ICU stay (days) & $11.4 \pm 13.69$ & $24.1 \pm 18.59$ & $7.0 \pm 7.62$ & $<.001$ & $20.6 \pm 16.87$ & $5.4 \pm 5.95$ & $<.001$ \\
\hline CRRT & & & & .47 & & & .54 \\
\hline Yes & $97(71.9 \%)$ & 23 & 74 & & 36 & 61 & \\
\hline No & $38(28.1 \%)$ & 12 & 26 & & 17 & 21 & \\
\hline IABP & & & & .04 & & & .11 \\
\hline Yes & $22(16.3 \%)$ & 4 & 18 & & 6 & 16 & \\
\hline No & $111(82.2 \%)$ & 29 & 82 & & 45 & 66 & \\
\hline Yes after ECMO weaning & $2(1.5 \%)$ & 2 & 0 & & 2 & 0 & \\
\hline ARF & & & & .005 & & & .35 \\
\hline Yes & $64(47.4 \%)$ & 9 & 55 & & 22 & 42 & \\
\hline No & $71(52.6 \%)$ & 26 & 45 & & 31 & 40 & \\
\hline ECMO time (hours) & $99.6 \pm 103.23$ & $124.1 \pm 76.69$ & $91.0 \pm 110.09$ & .10 & $128.13 \pm 82.20$ & $81.14 \pm 111.42$ & .01 \\
\hline Hypertension & & & & .23 & & & .11 \\
\hline Yes & $56(41.5 \%)$ & 11 & 45 & & 17 & 39 & \\
\hline No & $79(58.5 \%)$ & 24 & 55 & & 36 & 43 & \\
\hline $\mathrm{DM}$ & & & & .06 & & & .10 \\
\hline Yes & $51(37.8 \%)$ & 8 & 43 & & 15 & 36 & \\
\hline No & $84(62.2 \%)$ & 27 & 57 & & 38 & 46 & \\
\hline SAPS II & $84.45 \pm 18.40$ & $67.77 \pm 20.78$ & $90.29 \pm 13.30$ & $<.001$ & $74.90 \pm 20.81$ & $90.62 \pm 13.56$ & $<.001$ \\
\hline SOFA & $14.62 \pm 2.89$ & $12.62 \pm 3.49$ & $15.33 \pm 2.28$ & $<.001$ & $13.56 \pm 3.35$ & $15.26 \pm 2.35$ & .001 \\
\hline PDR & $88.06 \pm 20.05$ & $71.11 \pm 30.50$ & $94.00 \pm 9.36$ & $<.001$ & $78.96 \pm 27.28$ & $93.95 \pm 9.90$ & $<.001$ \\
\hline iCK-MB & $\begin{array}{l}45.30 \pm \\
112.77\end{array}$ & $24.25 \pm 75.01$ & $52.66 \pm 122.76$ & .20 & $24.94 \pm 66.54$ & $58.46 \pm 133.23$ & .09 \\
\hline iTroponin & $13.51 \pm 47.90$ & $7.21 \pm 21.03$ & $15.79 \pm 54.36$ & .37 & $5.99 \pm 17.63$ & $18.56 \pm 59.85$ & .14 \\
\hline iBUN & $24.36 \pm 20.07$ & $20.96 \pm 21.27$ & $25.56 \pm 19.61$ & .24 & $22.48 \pm 19.59$ & $25.58 \pm 20.41$ & .38 \\
\hline $\mathrm{iCr}$ & $1.90 \pm 2.28$ & $1.99 \pm 3.64$ & $1.86 \pm 1.58$ & .78 & $1.94 \pm 3.00$ & $1.87 \pm 1.68$ & .86 \\
\hline $\mathrm{ipH}$ & $7.02 \pm 0.19$ & $7.14 \pm 0.22$ & $6.98 \pm 0.15$ & $<.001$ & $7.12 \pm 0.20$ & $6.98 \pm 0.15$ & $<.001$ \\
\hline Lactate & $10.70 \pm 5.33$ & $7.09 \pm 4.93$ & $12.11 \pm 4.84$ & $<.001$ & $7.37 \pm 4.65$ & $12.44 \pm 4.86$ & $<.001$ \\
\hline BNP & $\begin{array}{c}712.12 \pm \\
1111.37\end{array}$ & $525.29 \pm 1164.03$ & $798.35 \pm 1090.82$ & .39 & $816.68 \pm 1462.18$ & $646.40 \pm 838.05$ & .58 \\
\hline pCK-MB & $\begin{array}{c}191.77 \pm \\
248.01\end{array}$ & $175.80 \pm 256.60$ & $197.36 \pm 246.01$ & .66 & $212.74 \pm 279.29$ & $178.21 \pm 226.29$ & .43 \\
\hline pTroponin & $\begin{array}{c}70.49 \pm \\
115.98\end{array}$ & $50.03 \pm 94.51$ & $77.65 \pm 122.23$ & .23 & $68.32 \pm 102.38$ & $71.89 \pm 124.57$ & .86 \\
\hline pBUN & $37.60 \pm 33.05$ & $34.84 \pm 20.46$ & $38.56 \pm 36.49$ & .57 & $43.59 \pm 29.84$ & $33.72 \pm 34.60$ & .09 \\
\hline $\mathrm{pCr}$ & $2.17 \pm 1.81$ & $2.15 \pm 2.17$ & $2.17 \pm 1.68$ & .94 & $2.33 \pm 1.97$ & $2.06 \pm 1.70$ & .39 \\
\hline pTB & $4.76 \pm 7.58$ & $4.61 \pm 5.78$ & $4.81 \pm 8.14$ & .90 & $6.29 \pm 7.34$ & $3.77 \pm 7.61$ & .06 \\
\hline
\end{tabular}

BMI, body mass index; ECMO, extracorporeal membrane oxygenation; AMI, acute myocardial infarction; ER, emergency room; CPR, cardiopulmonary resuscitation; E-CPR, extracorporeal cardiopulmonary resuscitation; OP, operation; HD, hospitalization day; ICU, intensive care unit; CRRT, continuous renal replacement therapy; IABP, intra-aortic balloon pump; ARF, acute renal failure; DM, diabetes mellitus; SAPS II, simplified acute physiology score II; SOFA, sepsis-related organ failure assessment; PDR, predicted death rate; BUN, blood urea nitrogen; Cr, creatinine; CK-MB, creatine kinase MB isoenzyme; TB, total bilirubin; BNP, brain natriuretic peptide. 
aggravated by septic shock, decompensated heart failure, and most commonly occurring postcardiotomy shock, failure to wean off CPB, and extracorporeal CPR [24].

2.4. ECMO and Cannulation. Each ECMO support was performed by a team of simultaneous cardiothoracic surgeons and intensivist physicians, and absolute hemodynamic criteria were applied in ECMO initiation. Before cannulation, patients received 3,000 to 5,000 IU of intravenous unfractionated heparin. After confirming activated clotting time greater than 180 seconds, peripheral cannulation for ECMO was performed. ECMO was instituted via peripheral cannulation, in which the femoral artery and vein were cannulated with single-lumen cannulae, for drainage from the infradiaphragmatic inferior vena cava and return into the iliac artery. Transthoracic central or carotid artery cannulation was not performed. Peripheral cannulation was done in all patients, and all these procedures were performed by both simultaneous cardiothoracic surgeons and intensivists [25]. A venous cannula was placed just below the right atrium through the femoral vein, and an arterial cannula was placed in the iliac artery via the femoral artery using the Seldinger technique under the guidance of ultrasound [26]. Our principle for cannulation is the application of ultrasonography and fluoroscopy. Prior to cannulation, ultrasonography was performed to assess vessel size and patency at potential sites of cannulation. For venous cannulation, the right internal jugular and both femoral veins were imaged in the supine position, and the compressibility and Doppler color flow were used to verify vein diameter and patency. For femoral arterial cannulation, the arterial diameter was also determined using the same maneuver used to measure the vein diameter with ultrasonography. Cannulae were selected to be at least of 2-Fr size smaller than the calculated vessel size in order to maintain distal limb perfusion of ipsilateral femoral arterial cannulation. Retrograde cannulation of the common or superficial femoral artery was not routinely performed. Only patients with femoral artery stenosis and insufficient diameter underwent the percutaneous approach, in which a 7- or 8-Fr retrograde cannula was inserted into the femoral artery and positioned distally to prevent the development of distal limb ischemia [27]. Patients without retrograde cannulation in the common or superficial femoral artery were more carefully identified and monitored for the development of limb ischemia by clinical examination or pulse oximetry as well as confirmative ultrasonography. Imaging was withheld during rapid deployment ECMO, such as the patients on extracorporeal CPR or the patients in whom delay in ECMO initiation could lead to significant deterioration or impending cardiac arrest.

2.5. ECMO Circuit System. All patients on VA ECMO support were managed on a Bioline heparin-coated Quadrox PLS circuit system (Maquet Cardiopulmonary AG, Hirrlingen, Germany). A single-stage cannula was applied for arterial cannulation (18 cm in length; 15-, 17-, 19-, and 21Fr) manufactured by Medtronic Bio-Medicus (Medtronic, Inc., Minneapolis, MN, USA), and a multistage cannula was applied for venous cannulation (60 cm in length; 19-, 21-, 23-, and 25-Fr) manufactured by Medtronic Bio-Medicus. The venous drainage and arterial return cannulae were inserted by the percutaneous Seldinger technique. In VA ECMO, the tip of the venous drainage cannula was positioned in the right atrium, and the arterial reinfusion cannula was inserted into the femoral artery. ECMO blood flow was adjusted to meet the hemodynamic and oxygen requirements of the patient. In some patients with renal insufficiency, continuous renal replacement therapy was integrated into the circuit.

2.6. ECMO Maintenance. The ultimate goal of ECMO application is to preserve all organs and to gain times for recovery. The metabolic panel and all laboratory test results were verified daily to identify proper organ perfusion and oxygenation. Arterial blood gas analysis (ABGA) and coagulation panels were obtained hourly, especially during the first day of ECMO support, and were verified at 2- or 4-hour intervals from the second day of ECMO support. The protective lung ventilation mode was preferred to allow pulmonary recovery if possible and necessary. According to hemodynamics and ABGA results, ECMO blood flow was adequately adjusted to maintain a cardiac index of $2.4 \mathrm{~L} / \mathrm{min} / \mathrm{m}^{2}$, a mixed venous oxygen saturation $\left(\mathrm{SvO}_{2}\right)$ level of around $70 \%$, and a mean arterial blood pressure of $70-75 \mathrm{~mm} \mathrm{Hg}$, and the oxygen flow $\left(\mathrm{FiO}_{2}\right)$ was controlled to maintain a postoxygenator partial oxygen pressure of $\geq 200 \mathrm{~mm} \mathrm{Hg}$. Inotropes and vasoconstrictors were administered to maintain baseline vital signs and to facilitate optimal myocardial recovery. Intra-aortic balloon pump (IABP) support was employed in cardiogenic shock patients to decrease afterload, increase coronary perfusion, and increase pulsatility. On the one hand, ECMO blood flow was adjusted sufficiently to keep enough systemic perfusion measured by urine output, plasma lactic acid levels, and mixed venous saturation. On the other hand, ECMO blood flow was adjusted to maintain enough lung circulation. Patients who received extracorporeal CPR and who exhibited a Glasgow Coma Scale score of $<9$ (eye response: eye opening to speech, motor: obedience to commands, verbal: intubated state) were applied to hypothermic therapy by maintaining their body temperature at $33^{\circ} \mathrm{C}-34^{\circ} \mathrm{C}$ for 24 hours and without administration of sedative drugs $[27,28]$. If the patient in hypothermia showed a Glasgow Coma Scale of $\geq 9$, their body temperature was increased at $0.2^{\circ} \mathrm{C} /$ hour, and the patient was immediately given sedative drugs to preserve neurologic function. Hematocrit was maintained at a level of $30 \%-35 \%$. Platelet count was maintained at $>100,000 / \mu \mathrm{L}$, and platelets were administered to maintain this level. Fresh frozen plasma, coagulation factors, and antithrombin III were administered on the basis of the laboratory test results and clinical necessity. To keep anticoagulation and to prevent clot formation in the oxygenator during ECMO support, intravenous heparin or nafamostat mesilate (SK Chemicals Life Science Biz., Seoul, Korea, licensed by Torii Pharmaceutical Co., Ltd., Tokyo, Japan) was continuously administered and titrated to achieve an activated clotting time of 160 to 200 seconds. Nafamostat mesilate was mainly applied for anticoagulation in cases of ECMO combined with continuous renal replacement therapy 
and was used in a dose of $0.4-1.5 \mathrm{mg} / \mathrm{kg} / \mathrm{hour}$ to maintain a partial thromboplastin time of $60-80$ seconds [29-32]. Patients who had not been on continuous renal replacement therapy were managed with intravenous unfractionated heparin alone. If there was any evidence of ongoing coagulopathy or hemorrhage, intravenous heparin or nafamostat mesilate was ceased. Daily scrubbing and dressing of the insertion site was done with povidone-iodine solution soap. If lung function did not fully recover during VA ECMO despite the restoration of heart function, then this led to upper body hypoxia $\left(\mathrm{PaO}_{2}<50 \mathrm{~mm} \mathrm{Hg}\right)$, the so-called harlequin syndrome. In such cases, the ECMO mode was changed to VAV ECMO, and these cases were excluded from the study [30-32].

2.7. Weaning from ECMO Support. Successful weaning was defined as weaning from ECMO support, followed by survival for more than 48 hours [33]. All patients received ECMO for at least 48 hours before weaning was attempted. The criteria included $\mathrm{SvO}_{2} \geq 70 \%$, hematocrit of $30 \%-35 \%$, absence of definite bleeding foci, tamponade or left heart distension, left ventricular ejection fraction $\geq 35 \%$, and normal blood lactic acid levels. Furthermore, it was essential to comprehensively identify that the patient's organ function fully recovered and stabilized from underlying disease. ECMO weaning was attempted when the patient on ECMO was hemodynamically stable by the minimal ECMO blood flow ( $<20 \%$ of total flow) with good recovery of myocardial contractility evidenced by echocardiography. The ECMO blood flow was decreased by 500 to $1,000 \mathrm{~mL} / \mathrm{min}$ for ECMO weaning. Once cardiac pulsatility and contractility improved, ECMO flow was reduced after optimizing inotropic infusion and ventilator setting. Finally, ECMO was withdrawn when sustained stability was noted in the patient's hemodynamic status [34-38].

2.8. Statistical Analysis. Statistical analyses were performed using IBM SPSS software (version 21; IBM Corp., Armonk, NY, USA) and using MedCalc for Windows, version 14.8 (MedCalc Software, Ostend, Belgium). Continuous variables were tested for normality using the Kolmogorov-Smirnov test. Continuous variables showing normality were analyzed using Student's $t$-test and expressed as the arithmetic mean \pm standard deviation, and continuous variables not showing normality were analyzed using the Mann-Whitney $U$ test and expressed as the median (25-75\% interquartile range). Categorical variables were displayed as frequency distribution and evaluated with Pearson's chi-square test or Fisher's exact test. Univariate comparisons between the groups for categorical variables were made using the chi-square test and Fisher's exact test as appropriate. Intergroup comparisons of nonnormally distributed continuous variables were made with the Mann-Whitney $U$ test. To avoid type 1 error, Bonferroni post hoc correction ( $\beta$-corrected) was applied to data that were initially deemed statistically significant by multiplying the number of variables by the $P$ value. Cox proportional hazards model was used to determine independent predictors of successful weaning. Overall survival was calculated according to the Kaplan-Meier method. Independent predictors of overall survival were also determined by using Cox proportional hazards model. Statistical significance was accepted at the 5\% level $(P<.05)$. To identify independent factors that were associated with patient death, we used univariate and multivariate stepwise logistic regression models. Multiple logistic regression analysis using backwards stepwise regression was performed. Variables with a level of significance defined as $P<.20$ for univariate logistic regression analysis, as well as clinically important variables, were entered as candidate variables in the multivariate models to assess their viability as independent predictors for postoperative ECMO. The results were reported as odds ratios (OR) with 95\% confidence intervals (CI) and relevant $P$ values. To assess the predictive power of the logistic regression model, a receiver operating characteristic (ROC) curves were used, and we calculated the area under the curve (AUC). Calibration was assessed using the Hosmer-Lemeshow goodness-of-fit test to compare the numbers of observed and predicted deaths in risk groups for the entire range of death probabilities. Discrimination was assessed using the area under the ROC curves. The areas under the ROC curves were compared by a nonparametric approach. This analysis was also utilized to calculate cutoff values, sensitivity, specificity, and overall correctness. Cumulative survival curves as a function of time were generated by the Kaplan-Meier approach and compared between groups using the log-rank test.

\section{Results}

A total of 135 patients who received VA ECMO at a single institution consisted of 94 (69.63\%) males and 41 (30.37\%) females, with a mean age of $59.44 \pm 16.55$ years. All the enrolled patients initially presented with cardiac arrest. Suitable indications for VA ECMO according to the ELSO guidelines were determined on the basis of final diagnosis immediately before discharge, but not initial diagnosis. The demographic and clinical characteristics of the study patients according to in-hospital mortality and ECMO weaning are summarized in Tables 1 and 2. Among the 135 patients, 35 (25.93\%) survived and were discharged uneventfully, and the remaining $100(74.07 \%)$ did not survive. The mean ages of the survivors and nonsurvivors were $51.91 \pm 17.63$ and $62.08 \pm 15.40$ years, respectively. Compared to the nonsurvivors, the survivors had a lower SAPS II (67.77 \pm 20.78 versus $90.29 \pm 13.30, P<.001)$, a lower SOFA score $(12.62 \pm 3.49$ versus $15.33 \pm 2.28, P<.001)$, a lower predicted death rate $(71.11 \pm 30.50$ versus $94.00 \pm$ 9.36, $P<.001)$, a higher ipH $(7.14 \pm 0.22$ versus $6.98 \pm 0.15, P<.001)$, and a lower lactate level $(7.09 \pm 4.93$ versus $12.11 \pm 4.84, P<.001)$. Furthermore, compared to the unsuccessful weaning group, the successful weaning group had a lower SAPS II $(74.90 \pm 20.81$ versus $90.62 \pm 13.56$, $P<.001)$, a lower SOFA score $(13.56 \pm 3.35$ versus $15.26 \pm$ $2.35, P=.001)$, a lower predicted death rate $(78.96 \pm$ 27.28 versus $93.95 \pm 9.90, P<.001)$, a higher ipH $(7.12 \pm$ 0.20 versus $6.98 \pm 0.15, P<.001)$, and a lower lactate level $(7.37 \pm 4.65$ versus $12.44 \pm 4.86, P<.001)$. CPR was more frequently performed in the unsuccessful weaning 
TABLE 2: Mean, standard error, and 95\% CI of survival days and ECMO weaning hours according to the age. Cumulative survival rates at 6, 10, and 30 days after ECMO initiation according to the age and cumulative ECMO weaning rates at 48, 72, and 192 hours after ECMO initiation according to the age subgroups.

\begin{tabular}{|c|c|c|c|c|c|}
\hline & Age $<50$ & $50 \leq$ age $<60$ & $60 \leq$ Age $<70$ & Age $\geq 70$ & Overall \\
\hline Mean survival days & 48.2 & 22.0 & 26.7 & 15.9 & 38.1 \\
\hline SE of survival days & 7.9 & 6.1 & 7.0 & 4.0 & 5.5 \\
\hline $95 \% \mathrm{CI}$ of survival days & $7.00-37.00$ & $4.00-15.00$ & $4.00-11.00$ & $4.00-9.00$ & $5.00-10.00$ \\
\hline \multicolumn{6}{|l|}{ Cumulative survival rates in 6 days } \\
\hline SP & 0.677 & 0.519 & 0.516 & 0.370 & 0.504 \\
\hline SE & 0.084 & 0.096 & 0.089 & 0.071 & 0.043 \\
\hline \multicolumn{6}{|l|}{ Cumulative survival rates in 10 days } \\
\hline SP & - & 0.407 & 0.355 & 0.304 & 0.407 \\
\hline SE & - & 0.094 & 0.085 & 0.067 & 0.042 \\
\hline \multicolumn{6}{|l|}{ Cumulative survival rates in 30 days } \\
\hline SP & - & 0.18 & - & 0.152 & 0.273 \\
\hline SE & - & 0.083 & - & 0.058 & 0.040 \\
\hline Mean ECMO weaning hours & 224.6 & 165.8 & 149.3 & 126.6 & 175.6 \\
\hline SE of ECMO weaning hours & 30.0 & 28.6 & 34.3 & 22.7 & 21.7 \\
\hline 95\% CI of ECMO weaning hours & $165.30-283.01$ & $109.81-221.78$ & $81.99-216.58$ & $82.07-171.04$ & $133.04-218.17$ \\
\hline \multicolumn{6}{|c|}{ Cumulative ECMO weaning rates in 48 hours } \\
\hline SP & 0.762 & - & - & 0.644 & 0.662 \\
\hline SE & 0.078 & - & - & 0.071 & 0.041 \\
\hline \multicolumn{6}{|c|}{ Cumulative ECMO weaning rates in 72 hours } \\
\hline SP & - & - & - & 0.468 & 0.569 \\
\hline SE & - & - & - & 0.077 & 0.044 \\
\hline \multicolumn{6}{|c|}{ Cumulative ECMO weaning rates in 192 hours } \\
\hline SP & 0.527 & 0.406 & 0.245 & - & 0.366 \\
\hline $\mathrm{SE}$ & 0.113 & 0.109 & 0.101 & - & 0.049 \\
\hline
\end{tabular}

ECMO, extracorporeal membrane oxygenation; CI, confidence interval; SE, standard error; SP, survival proportion.

group $(85.3 \%[70 / 82]$ versus $60.3 \%[32 / 53], P=.002)$, and extracorporeal CPR was more frequently performed in the unsuccessful weaning group (74.3\% [61/82] versus $49.0 \%$ [26/53], $P=.005)$. Cardiac arrest more frequently developed in the unsuccessful weaning group $(85.3 \%$ [70/82] versus $58.57 \%$ [31/53], $P=.001)$, in-hospital cardiac arrest more frequently developed in the nonsurvivors (91.0\% [61/67] versus $8.9 \%$ [6/67], $P<.001)$, and out-hospital cardiac arrest more frequently occurred in the survivors $(61.7 \%$ [21/34] versus $38.2 \%[13 / 34], P=.001)$. However, there was no significant difference in the application of continuous renal replacement therapy (CRRT), CPR time, pump type, ECMO type, gender, height, body weight, BMI, anticoagulation, admission route, combined operation, or underlying acute renal failure/hypertension/diabetes mellitus between the successful weaning and unsuccessful weaning groups. Furthermore, there was no significant difference in the level of CK$\mathrm{MB}$, troponin, blood urea nitrogen (BUN), or Cr between the successful and unsuccessful weaning groups (Tables 1 and 2). After univariate logistic regression analysis of initial factors for VA ECMO support, the SAPS II $(\mathrm{OR}=1.079,95 \% \mathrm{CI}$ $1.047-1.111, P<.001)$, age $(\mathrm{OR}=1.304,95 \%$ CI $1.087-1.565$, $P=.004), \mathrm{ipH}(\mathrm{OR}=0.314,95 \%$ CI $0.188-0.525, P<.001)$, hospital stay $(\mathrm{OR}=0.863,95 \%$ CI $0.819-0.909, P<.001)$, $\mathrm{ECPR}(\mathrm{OR}=0.173,95 \% \mathrm{CI} 0.075-0.399, P<.001)$, acute renal failure $(\mathrm{OR}=0.283,95 \%$ CI $0.120-0.665, P=.004)$, cardiac arrest $(\mathrm{OR}=0.148,95 \%$ CI $0.062-0.352, P<.001)$, and CPR $(\mathrm{OR}=0.166,95 \%$ CI $0.0705-0.3941, P<.001)$ were associated with in-hospital VA ECMO mortality. The other variables were not associated with in-hospital VA ECMO mortality in univariate logistic regression analysis. After multivariate logistic regression analysis of initial factors for VA ECMO support, the SAPS II (OR = 1.101, 95\% CI 1.005-1.208, $P=$ $.04)$, ipH $(\mathrm{OR}=0.001,95 \%$ CI $0.000-0.863, P=.045)$, and hospital stay $(\mathrm{OR}=0.814,95 \%$ CI $0.734-0.902, P<.001)$ were associated with in-hospital VA ECMO mortality. The other variables, such as age $(P=.8256), \operatorname{ECPR}(P=.51)$, acute renal failure $(P=.7018)$, cardiac arrest $(P=.9957)$, or CPR $(P=.73)$, were not associated with in-hospital VA ECMO mortality in multivariate logistic regression analysis. To evaluate the in-hospital mortality according to age, patients were stratified into 8 groups according to age. The survivors were noted in younger age groups $\left(P=.02\right.$, chi-square test $\left[x^{2}=\right.$ $17.102])$, and the number of survivors decreased with age $\left(P=.003\right.$, chi-square test for trend $\left.\left[x^{2}=8.688\right]\right)$ (Table 3$)$. Post hoc analysis was performed by using the StudentNewman-Keuls test, and there was a significant difference between the age groups. Post hoc Student-Newman-Keuls test results for all pairwise comparisons are summarized in Table 3. 


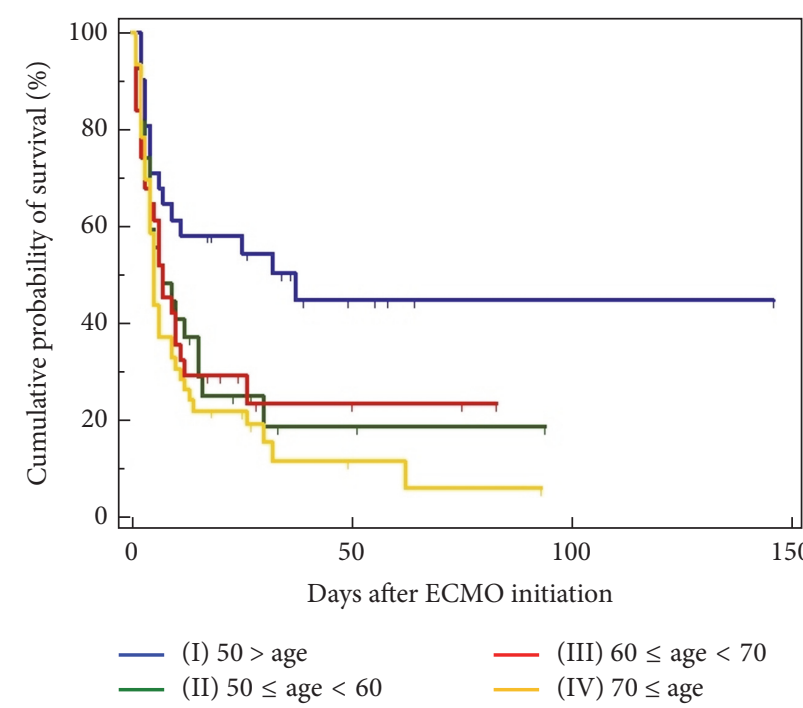

Figure 1: Kaplan-Meier curves for the cumulative survival probability of a pre-ECMO age. To predict in-hospital mortality according to age, patients were divided into 4 groups according to age: group I (age $<50, n=31)$, group II ( $50 \leq$ age $<60, n=27)$, group III $(60 \leq$ age $<70, n=31)$, and group IV $(70 \leq$ age, $n=46)$. Comparison of survival curves with the log-rank test: chi-square test $x^{2}=11.2779$, df $=3, P=.0103$. Mean, standard error, and 95\% confidence intervals for the mean are summarized in Table 2. Comparison of survival probabilities at 6,10 , and 30 days after ECMO initiation with the log-rank test and hazard ratios with $95 \%$ confidence intervals is also summarized in Tables 2 and 4. Overall mean survival rate was $25.9 \%$, 6-day survival rate was $50 \%, 10$-day survival rate was $40.7 \%$, and 30 -day survival rate was $27.3 \%$.

TABLE 3: In-hospital mortality according to age.

\begin{tabular}{lcccc}
\hline & $\begin{array}{c}\text { All patients } \\
(n=135)\end{array}$ & $\begin{array}{c}\text { Survivors } \\
(n=35)\end{array}$ & $\begin{array}{c}\text { Nonsurvivors } \\
(n=100)\end{array}$ & $\begin{array}{c}P \\
.0167\end{array}$ \\
\hline Age $<50$ & $31(23.0 \%)$ & 15 & 15 & \\
$50 \leq$ age $<55$ & $17(12.6 \%)$ & 2 & 15 & \\
$55 \leq$ age $<60$ & $10(7.4 \%)$ & 4 & 6 & \\
$60 \leq$ age $<65$ & $12(8.9 \%)$ & 2 & 10 & \\
$65 \leq$ age $<70$ & $19(14.1 \%)$ & 6 & 13 & \\
$70 \leq$ age $<75$ & $27(20.0 \%)$ & 5 & 22 & \\
$75 \leq$ age $<80$ & $9(6.7 \%)$ & 1 & 8 & \\
Age $\geq 80$ & $10(7.4 \%)$ & 0 & 10 & \\
\hline$P$
\end{tabular}

$P$, chi-square test: $x^{2}=17.102, P=.0167$, chi-square test for trend: $x^{2}=$ $8.688, P=.0032$.

To predict in-hospital survival and ECMO weaning, patients were divided into 4 groups according to age: group I (age $<50, n=31$ ), group II $(50 \leq$ age $<60, n=27)$, group III ( $60 \leq$ age $<70, n=31$ ), and group IV (age $\geq$ $70, n=46)$. The mean, standard error, $95 \%$ CI for the mean, median, and 95\% CI for the mean about survival are summarized in Table 2. In the Kaplan-Meier analysis, 6-day cumulative survival rates ( \pm standard error) in groups I to IV were $0.67 \pm 0.084,0.51 \pm 0.09,0.51 \pm 0.08,0.37 \pm 0.07$, and $0.50 \pm$ 0.04 , respectively (Figure 1). Furthermore, in the KaplanMeier analysis, 30-day cumulative survival rates ( \pm standard
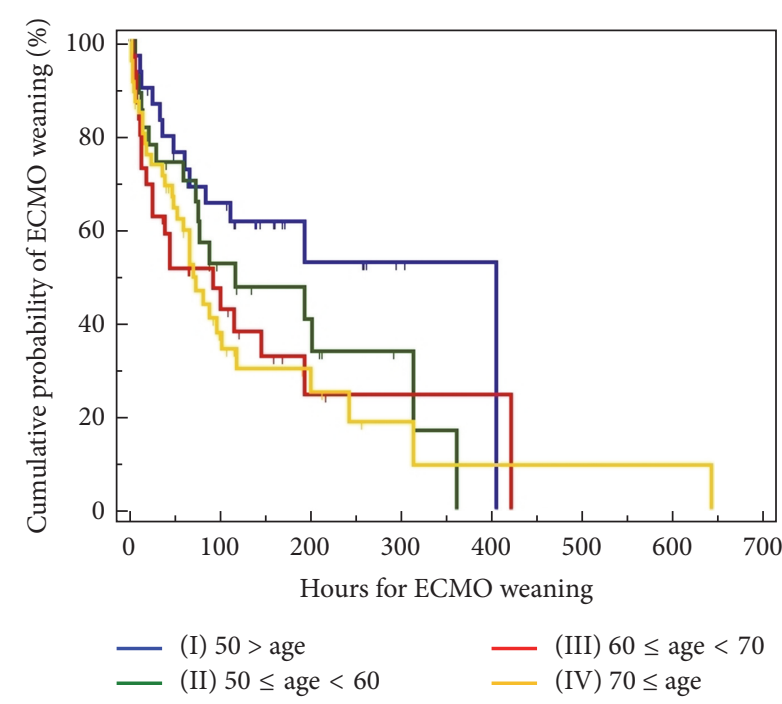

Figure 2: Kaplan-Meier curves for the cumulative ECMO weaning probability of a pre-ECMO age. To predict in-hospital mortality according to age, patients were divided into 4 groups: group I (age $<50, n=31)$, group II $(50 \leq$ age $<60, n=27)$, group III $(60 \leq$ age $<70, n=31)$, and group IV $(70 \leq$ age, $n=46)$. Comparison of survival curves with the log-rank test: chi-square test $x^{2}=5.9915, \mathrm{df}=3, P=.1120$. Mean, standard error, and 95\% confidence intervals for the mean are summarized in Table 2. Comparison of ECMO weaning probabilities at 48, 72, and 192 hours after ECMO initiation with the log-rank test and hazard ratios with 95\% confidence intervals is also summarized in Tables 2 and 4. Overall mean ECMO weaning rate was $39.20 \%$, 8-day mean ECMO weaning rate was $50 \%, 10$-day mean ECMO weaning rate was $45.8 \%$, and 30 -day mean ECMO weaning rate was $37.4 \%$.

error) in group II, group IV, and the entire patients group were $0.18 \pm 0.08,0.15 \pm 0.05$, and $0.27 \pm 0.04$, respectively (Table 2). In the Kaplan-Meier analysis, the lower age groups showed higher 6-day, 30-day, and overall cumulative survival rates (comparison of survival curves by the log-rank test: chisquare test $\left.x^{2}=11.27, \mathrm{df}=3, P=.01\right)$. The mean, standard error, and 95\% CI for the mean about ECMO weaning are summarized in Table 2. In the Kaplan-Meier analysis, 48hour cumulative successful ECMO weaning rates ( \pm standard error) in group I, group IV, and the entire patients group were $0.76 \pm 0.07,0.64 \pm 0.07$, and $0.66 \pm 0.04$, respectively (Figure 2). Furthermore, in the Kaplan-Meier analysis, 192hour cumulative survival rates ( \pm standard errors) in group I, group II, group III, and the entire patients group were $0.52 \pm 0.11,0.40 \pm 0.10,0.24 \pm 0.10$, and $0.36 \pm 0.04$, respectively (Table 2). In the Kaplan-Meier analysis, the lower age groups showed higher 48-hour, 192-hour, and overall cumulative ECMO weaning rates (comparison of survival curves by the log-rank test: chi-square test $x^{2}=5.99, \mathrm{df}=3, P=.11$ ). Compared to group I, hazard ratios with $95 \%$ CI in groups II to IV were 1.60 with 0.85 to $2.99,2.04$ with 1.07 to 3.89 , and 2.05 with 1.16 to 3.63 , respectively. Compared to group II, hazard ratios with $95 \% \mathrm{CI}$ in groups III and IV were 1.27 with 0.65 to 2.50 and 1.28 with 0.70 to 2.34 , respectively. Compared to group III, hazard ratios with $95 \% \mathrm{CI}$ in group 
TABLE 4: Hazard ratios with 95\% confidence intervals about survival probability and ECMO weaning probability according to age.

\begin{tabular}{|c|c|c|c|c|}
\hline & Age $<50$ & $50 \leq$ age $<60$ & $60 \leq$ age $<70$ & Age $\geq 70$ \\
\hline \multicolumn{5}{|c|}{ Hazard ratios with $95 \%$ confidence intervals about survival probability according to age } \\
\hline Age $<50$ & - & $\begin{array}{c}1.87 \\
0.99 \text { to } 3.54\end{array}$ & $\begin{array}{c}2.90 \\
1.70 \text { to } 4.97\end{array}$ & $\begin{array}{c}5.71 \\
3.38 \text { to } 9.65\end{array}$ \\
\hline $50 \leq$ age $<60$ & $\begin{array}{c}0.53 \\
0.28 \text { to } 1.01\end{array}$ & - & $\begin{array}{c}1.55 \\
0.83 \text { to } 2.90\end{array}$ & $\begin{array}{c}3.05 \\
1.65 \text { to } 5.63\end{array}$ \\
\hline $60 \leq$ age $<70$ & $\begin{array}{c}0.34 \\
0.20 \text { to } 0.59\end{array}$ & $\begin{array}{c}0.65 \\
0.35 \text { to } 1.21\end{array}$ & - & $\begin{array}{c}1.97 \\
1.18 \text { to } 3.27\end{array}$ \\
\hline Age $\geq 70$ & $\begin{array}{c}0.18 \\
0.10 \text { to } 0.30\end{array}$ & $\begin{array}{c}0.33 \\
0.18 \text { to } 0.61\end{array}$ & $\begin{array}{c}0.51 \\
0.31 \text { to } 0.84\end{array}$ & - \\
\hline \multicolumn{5}{|c|}{ Hazard ratios with 95\% confidence intervals about ECMO weaning probability according to age } \\
\hline Age $<50$ & - & $\begin{array}{c}1.60 \\
0.86 \text { to } 3.00\end{array}$ & $\begin{array}{c}2.0 \\
1.08 \text { to } 3.89\end{array}$ & $\begin{array}{c}2.06 \\
1.16 \text { to } 3.63\end{array}$ \\
\hline $50 \leq$ age $<60$ & $\begin{array}{c}0.62 \\
0.33 \text { to } 1.17\end{array}$ & - & $\begin{array}{c}1.28 \\
0.65 \text { to } 2.50\end{array}$ & $\begin{array}{c}1.28 \\
0.70 \text { to } 2.34\end{array}$ \\
\hline $60 \leq$ age $<70$ & $\begin{array}{c}0.49 \\
0.2570 \text { to } 0.9268\end{array}$ & $\begin{array}{c}0.78 \\
0.40 \text { to } 1.53\end{array}$ & - & $\begin{array}{c}1.00 \\
0.54 \text { to } 1.86\end{array}$ \\
\hline Age $\geq 70$ & $\begin{array}{c}0.4865 \\
0.28 \text { to } 0.86\end{array}$ & $\begin{array}{c}0.78 \\
0.43 \text { to } 1.42\end{array}$ & $\begin{array}{c}1.00 \\
0.54 \text { to } 1.85\end{array}$ & - \\
\hline
\end{tabular}

ECMO, extracorporeal membrane oxygenation.

IV was 1.00 with 0.54 to 1.86 (Table 4 ). Mean survival times (with 95\% CI for the mean) at the cutoff age of 50 ( $<50$ versus $\geq 50$ years), 60 ( $<60$ versus $\geq 60$ years), 70 ( $<70$ versus $\geq 70$ ), and 80 ( $<80$ versus $\geq 80$ years) were 48.23 days with 32.72 to 63.74 versus 27.84 days with 16.99 to $38.68,53.92$ days with 36.61 to 71.22 versus 19.30 days with 11.93 to $26.66,46.70$ days with 33.37 to 60.03 versus 16.18 days with 7.64 to 24.72 , and 40.05 days with 28.63 to 51.47 versus 6.62 days with 3.80 to 9.44 , respectively. The overall survival time was 38.07 days with 27.25 to 48.89 . In the Kaplan-Meier analysis, the cutoff ages of 50, 60, and 70 exhibited significant differences in cumulative survival rates (comparison of survival curves by the log-rank test: cutoff 50; chi-square test $x^{2}=9.89, P=$ .0017; cutoff 60: chi-square test $x^{2}=6.88, P=.01$; cutoff 70: chi-square test $x^{2}=4.58, P=.03$; cutoff 80 : chi-square test $\left.x^{2}=2.53, P=.11\right)$. At the cutoff age of 50 , hazard ratio with $95 \%$ CI in patients aged $\geq 50$ years was 1.53 with 0.97 to 2.40 . At the cutoff age of 60 , hazard ratio with $95 \% \mathrm{CI}$ in patients aged $\geq 60$ years was 1.65 with 1.12 to 2.45 . At the cutoff age of 70 , hazard ratio with $95 \%$ CI in patients aged $\geq 60$ years was 1.53 with 0.97 to 2.40 . At the cutoff age of 70 , hazard ratio with $95 \% \mathrm{CI}$ in patients aged $\geq 60$ years was 1.73 with 0.69 to 4.33 .

\section{Discussion}

Actually, VA ECMO is an option for circulatory support, and various ventricular assist devices implanted both surgically and percutaneously are other options. The benefits of VA ECMO over other options for circulatory support could be summarized as follows: (1) being an easy method for emergent insertion, (2) potential effectiveness in biventricular support, and (3) capability to simultaneously provide respiratory support [20]. Furthermore, VA ECMO provides adequate temporary perfusion and oxygenation to organs in cardiac arrest patients [21,23]. VA ECMO might be used as a bridge to myocardial recovery and heart transplantation or a permanent ventricular assist device. Despite all these advantages, the hospital mortality rates of patients who received ECMO support have been reported to be approximately $60 \%$ [39-41]. In the recent cohorts with post-acute myocardial infarction (AMI) cardiogenic shock, it has been reported that advanced age, female gender, myocardial infarction, onsetto-percutaneous coronary intervention (PCI) time, evidence of end-organ hypoperfusion, left main coronary disease or total occlusion of the left anterior descending artery, 3vessel coronary artery disease, hypoxic brain damage, and decreased renal function are independent negative factors for increased in-hospital mortality. However, since these results are limited to patients with post-AMI cardiogenic shock, they could not be generally applied to those with cardiogenic shock on VA ECMO support [42-47]. The selection of appropriate candidates is especially important for successful ECMO treatment, and ECMO treatment requires specialized medical staff and equipment. Thus, outcome prediction for ECMO is mandatory, though it requires enormous expenditure. Outcome prediction for ECMO is also valuable because it is associated with the ethical problem of whom must be cared for with ECMO support. Another important perspective is the emergent nature of ECMO treatment, for which we may have difficulty in comprehensive discussion as to whether ECMO should be initiated or not [48-50].

To make impartial scoring systems for identifying appropriate patient candidates for ECMO, Schmidt et al. [51, 52] evaluated the predicting death for severe acute respiratory distress syndrome (ARDS) on VV ECMO (PRESERVE) and respiratory extracorporeal membrane oxygenation survival prediction (RESP) scores in their survival prediction model for patients who received ECMO support in the intensive 
care unit (ICU). Klinzing et al. [53, 54] demonstrated that the PRESERVE and RESP scoring systems fail to predict mortality for patients receiving VA ECMO. The EuroSCORE was designed to predict the mortality of patients undergoing cardiac surgery and may correlate with the outcomes of postcardiotomy failure patients. The same study assessed patients treated with ECMO for refractory postcardiotomy shock and found that a EuroSCORE of $>20 \%$ is associated with mortality [55]. Classically, renal function is an important factor for ECMO survival and intimately related to metabolic acidosis and a high lactate level [56-58]. In our study, factors associated with renal injury, such as $\mathrm{Cr}$ or BUN, showed little statistical significance, and increased lactate levels were closely related to prediction of mortality in the study patients, but the SAPS II or ipH was not so [59, 60]. Mehta et al. [61, 62] suggested that blood pressure is a key bedside tool to predict postoperative dialysis risk in patients undergoing cardiac surgery. Damaged cardiac function leads to low cardiac output and then hypoperfusion, subsequently precipitating prerenal acute kidney injury $[63,64]$.

In a study conducted by Klinzing et al. [53], age of $>75$ years was an absolute contraindication to ECMO therapy. Furthermore, in the PRESERVE score proposed by Schmidt et al. [52], advanced age is classified as a very high mortality risk factor (ages < 45, 0 point; ages $45-55,2$ points; and ages $>$ 55,3 points), whereas in the RESP score proposed by Schmidt et al. [51], advanced age is also categorized as a very high mortality risk factor (ages $<50,0$ point; ages $50-59,-2$ points; and ages $\geq 60,-3$ points). In the score proposed by Roch et al. [65], age of $\geq 45$ is also classified as high in-hospital mortality. As such, most scoring systems concerning ECMO regard advanced age as an absolute contraindication to ECMO or a very high-risk factor and sometimes recommend never to perform ECMO in old age. Recently, Schmidt et al. [47] also reported new scoring system using 12 pre-ECMO parameters, called the survival after VA ECMO (SAVE) score, to identify pre-ECMO factors which influence survival rate in refractory cardiogenic shock patients requiring ECMO. In the SAVE score system proposed by Schmidt et al. [47], advanced age is also classified as a very high mortality parameter (ages 18-38, 7 scores; ages 39-52, 4 scores; ages 53-62, 3 scores; and ages $\geq 63$, 0 scores). In 2016, Chen et al. [66] assessed that the SAVE score is a more acceptable scoring system to predict 90-day mortality for patients who received VA ECMO support in the emergency department rather than PRESERVE or RESP score system and an independent variable in the Cox proportional hazards regression model. They also reported that the combination of blood lactic acid level and SAVE score, termed the modified SAVE score, shows more improved discrimination of outcome predictions for patients who receive VA ECMO support in the emergency department $[66,67]$.

Although many studies reported that advanced age is a great risk factor in VA ECMO mortality, unfortunately there are no definite risk measurement tools that can predict the probability of survival in patients requiring VA ECMO. In our study, patients at younger age showed a higher survival rate with statistical significance $(P=.02$, chi-square test: $\left.x^{2}=17.102\right)$, and the number of survivors was significantly decreased with age $(P=.003$, chi-square test for trend: $\left.x^{2}=8.688\right)$. Furthermore, in our study, there were significant differences in survival between age groups, and older age showed a lower survival rate with statistical significance $(P=.01)$. By univariate logistic regression analysis, age was significantly associated with in-hospital mortality $(\mathrm{OR}=$ 1.30, $P=.004)$, whereas, by multivariate logistic regression analysis, it was not significantly associated with in-hospital mortality $(P=.83)$. Furthermore, age was not significantly associated with VA ECMO weaning $(P=.11)$. Additionally, the multivariate Cox regression analysis showed that age is not a significant predictor of hospital mortality or VA ECMO weaning ( $P=.86$ and $P>.99$, resp.). Therefore, it is thought that an age criterion is not a main significant variable for predicting in-hospital mortality or VA ECMO weaning. As previously mentioned, advanced age is not a definite criterion for ECMO treatment, and thus most studies have adopted self-made age criteria, especially advanced age. Thus, further studies on advanced age are needed to confirm our results.

Furthermore, emerging cardiopulmonary assist technique enables physicians to have an opportunity for further evaluation and diagnosis, thereby facilitating appropriate ECMO treatment [68-70]. Therefore, ECMO should be primarily considered in high-risk acute myocardial infarction (AMI) patients with cardiogenic shock or cardiac arrest, regardless of age. In fact, advanced age is the most common risk factor for increased morbidity and mortality in many disease entities and delays or obstructs full recovery from underlying disease [71-77]. However, candidates for VA ECMO should be determined with biological age, but not with calendar age itself. Prompt evaluation and decision are essential to patients who require VA ECMO. It is very difficult to establish criteria for appropriate ECMO and to evaluate whether patients with acute cardiopulmonary failure would respond to conventional treatment. Advanced age is a significant risk factor for VA ECMO treatment; however, a more important factor is physiologic status, but not age itself. Thus, patients of advanced age should not be excluded from the chance of recovery after VA ECMO treatment. Although the great predictive value of scoring systems will remain one of the biggest challenges to physicians, the scoring systems could facilitate communication of objective prognostic information for decision-making by family members and surrogates and may help physicians increase the chance of patient survival and avoid a waste of healthcare services.

Our study has several limitations. First, it was conducted at a single institution, which limited the generalizability of study results. Secondly, our study population was relatively small and had multiple underlying diseases indicated for VA ECMO. Thirdly, despite a study about VA ECMO, a relatively small number of patients with refractory septic shock were enrolled in the study. Fourthly, since our study only focused on VA ECMO, it is difficult to generalize our results to other forms of ECMO, such as VV ECMO. Further studies using various forms of ECMO are warranted. Our study only focused on initial modalities at the decision point of ECMO, and long-term outcomes were not 
evaluated. evaluated. Fifthly, serum biomarkers, such as brain natriuretic peptide, were not measured in our study. The brain natriuretic peptide is known as a predictor of the outcomes after severe cardiac failure [78]. Further studies are needed to determine whether our results could be accurately applied to such patients. Finally, we performed retrospective analysis, so that additional prospective multicenter studies are needed to confirm our results. Future research should develop more simplified VA ECMO scoring systems with a larger sample size to accurately predict VA ECMO mortality.

\section{Conclusion}

Despite established ELSO indications in ECMO, cardiac indications for VA ECMO may differ greatly among physicians and centers; therefore, it is absolutely important to determine which patients should be treated with VA ECMO. In most reports on ECMO treatment, advanced age is classified as an absolute contraindication to VA ECMO application, so that VA ECMO is not recommended for patients of advanced age. Since ECMO support for adult populations with refractory cardiogenic shock has been exponentially increasing, a comprehensive analysis of risk factors associated with advanced age must be completed. In most studies about VA ECMO, advanced age is regarded as a main significant risk factor and contraindication to VA ECMO treatment; however, a more important factor is physiologic status, but not age. Therefore, patients of advanced age should not be excluded from the chance of recovery with VA ECMO treatment. Additionally, advanced age could be regarded as a major risk factor for VA ECMO; however, it should not be considered an absolute contraindication to VA ECMO. Furthermore, patients who need VA ECMO treatment should be evaluated with impartial predicting systems based on physiologic variables other than age itself.

\section{Abbreviations}

ECMO: Extracorporeal membrane oxygenation

VA: Venoarterial

ELSO: Extracorporeal life support organization

ECLS: Extracorporeal life support

IABP: Intra-aortic balloon pump

CPB: Cardiopulmonary bypass

VV: Venovenous

CESAR: Conventional ventilatory support versus extracorporeal membrane oxygenation for severe adult respiratory failure

VAV: Venoarterial venous

BMI: Body mass index

ECPR: Extracorporeal cardiopulmonary resuscitation

CPR: Cardiopulmonary resuscitation

ICU: Intensive care unit

EM: $\quad$ Emergency department

SOFA: Sepsis-related organ failure assessment

SAPS II: Simplified acute physiology score II
AKIN:
Acute kidney injury network
RIFLE:
Risk, injury, failure, loss of kidney
function, and end-stage kidney disease
Cr: $\quad$ Serum creatinine
PMP: $\quad$ Polymethylpentene
ARDS: $\quad$ Acute respiratory distress syndrome
PRESERVE: Predicting death for severe acute respiratory distress syndrome on $\mathrm{VV}$ ECMO
RESP: Respiratory extracorporeal membrane
SAVE: $\quad$ Survival after VA ECMO
AMI: $\quad$ Acute myocardial infarction
OR: $\quad$ Odds ratios
CI: $\quad$ Confidence intervals
ROC: $\quad$ Receiver operating characteristic
AUC: $\quad$ Area under the curve.

\section{Ethical Approval}

The present study was approved by the Ethics Committee and the Institutional Review Board (2013-105, Hallym University Chuncheon Sacred Heart Hospital, Hallym University, Republic of Korea).

\section{Conflicts of Interest}

The authors declare that they have no conflicts of interest.

\section{Authors' Contributions}

WooSurng Lee conceived and designed the study, collected and interpreted the data, and drafted the manuscript. HyoungSoo Kim, SunHee Lee, HeeSung Lee, and HyunHee Choi collected and interpreted the data. WooSurng Lee, YoHan Kim, and YoHan Kim analyzed and interpreted the data and performed the statistical analyses. SeongJoon Cho, SeMin Ryu, and SungMin Park participated in the study design and helped to revise the manuscript. HyoungSoo Kim, WooSurng Lee, and HeeSung Lee revised the manuscript. HyunKeun Chee, JunSeok Kim, JaeJoon Hwang, and SongAm Lee helped to perform statistical analyses and revised the results of statistical analyses. All authors read and approved the final manuscript and agreed to be accountable for all aspects of the work.

\section{References}

[1] J. H. Gibbon Jr., "Application of a mechanical heart and lung apparatus to cardiac surgery," Minnesota medicine, vol. 37, no. 3, pp. 171-185, 1954.

[2] W. Dorson, E. Baker, M. L. Cohen et al., "A perfusion system for infants," Transactions-American Society for Artificial Internal Organs, vol. 15, no. 1, pp. 155-160, 1969.

[3] J. J. White, H. G. Andrews, H. Risemberg, D. Mazur, and J. A. Haller Jr., "Prolonged respiratory support in newborn infants with a membrane oxygenator," Surgery, vol. 70, no. 2, pp. 288296, 1971. 
[4] G. MacLaren, A. Combes, and R. H. Bartlett, "Contemporary extracorporeal membrane oxygenation for adult respiratory failure: life support in the new era," Intensive Care Medicine, vol. 38, no. 2, pp. 210-220, 2012.

[5] K. Shekar, D. V. Mullany, B. Thomson, M. Ziegenfuss, D. G. Platts, and J. F. Fraser, "Extracorporeal life support devices and strategies for management of acute cardiorespiratory failure in adult patients: a comprehensive review," Critical Care, vol. 18, no. 3, p. 219, 2014.

[6] J. D. Hill, T. G. O’Brien, J. J. Murray et al., "Prolonged extracorporeal oxygenation for acute post-traumatic respiratory failure (shock-lung syndrome). Use of the Bramson membrane lung," New England Journal of Medicine, vol. 286, no. 12, pp. 629-634, 1972.

[7] D. Sidebotham, S. J. Allen, A. McGeorge, N. Ibbott, and T. Willcox, "Venovenous extracorporeal membrane oxygenation in adults: practical aspects of circuits, cannulae, and procedures," Journal of Cardiothoracic and Vascular Anesthesia, vol. 26, no. 5, pp. 893-909, 2012.

[8] T. J. Preston, T. M. Ratliff, D. Gomez et al., "Modified surface coatings and their effect on drug adsorption within the extracorporeal life support circuit," Journal of Extra-Corporeal Technology, vol. 42, no. 3, pp. 199-202, 2010.

[9] S. Agati, G. Ciccarello, N. Fachile et al., "DIDECMO: a new polymethylpentene oxygenator for pediatric extracorporeal membrane oxygenation," ASAIO Journal, vol. 52, no. 5, pp. 509$512,2006$.

[10] S. Horton and T. R. Karl, "Extracorporeal membrane oxygenation using a centrifugal pump," Annals of Thoracic Surgery, vol. 64, no. 5, p. 1528, 1997.

[11] C. A. Bermudez, R. V. Rocha, P. L. Sappington, Y. Toyoda, H. N. Murray, and A. J. Boujoukos, "Initial experience with single cannulation for venovenous extracorporeal oxygenation in adults," The Annals of Thoracic Surgery, vol. 90, no. 3, pp. 991$995,2010$.

[12] J. P. Herlihy, P. Loyalka, G. Jayaraman, B. Kar, and I. D. Gregoric, "Extracorporeal membrane oxygenation using the TandemHeart System's catheters," Texas Heart Institute Journal, vol. 36, no. 4, pp. 337-341, 2009.

[13] K. Ramanathan, M. E. Cove, M. G. Caleb, K. L. K. Teoh, and G. Maclaren, "Ethical dilemmas of adult ECMO: emerging conceptual challenges," Journal of Cardiothoracic and Vascular Anesthesia, vol. 29, no. 1, pp. 229-233, 2015.

[14] Extracorporeal Life Support Registry Report, https://www.elso .org/Portals/0/IGD/Archive/FileManager/e76ef78eabcusersshyerdocumentselsoguidelinesforadultcardiacfailure1.3.pdf.

[15] Extracorporeal Life Support Registry Report, https://www.elso .org/Portals/0/IGD/Archive/FileManager/989d4d4d14cusersshyerdocumentselsoguidelinesforadultrespiratoryfailure1.3.pdf.

[16] J. F. Fraser, K. Shekar, S. Diab et al., "ECMO—the clinician's view," ISBT Science Series, vol. 7, no. 1, pp. 82-88, 2012.

[17] G. J. Peek, M. Mugford, R. Tiruvoipati et al., "Efficacy and economic assessment of conventional ventilatory support versus extracorporeal membrane oxygenation for severe adult respiratory failure (CESAR): a multicentre randomised controlled trial," The Lancet, vol. 374, no. 9698, pp. 1351-1363, 2009.

[18] J.-L. Vincent, R. Moreno, J. Takala et al., "The SOFA (Sepsisrelated Organ Failure Assessment) score to describe organ dysfunction/failure," Intensive Care Medicine, vol. 22, no. 7, pp. 707-710, 1996.
[19] W. A. Knaus, E. A. Draper, D. P. Wagner, and J. E. Zimmerman, "APACHE II: a severity of disease classification system," Critical Care Medicine, vol. 13, no. 10, pp. 818-829, 1985.

[20] R. L. Mehta, J. A. Kellum, S. V. Shah et al., "Acute kidney injury network: report of an initiative to improve outcomes in acute kidney injury," Critical care (London, England), vol. 11, no. 2, article R31, 2007.

[21] Z. Ricci, D. N. Cruz, and C. Ronco, "Classification and staging of acute kidney injury: beyond the RIFLE and AKIN criteria," Nature Reviews Nephrology, vol. 7, no. 4, pp. 201-208, 2011.

[22] The Extracorporeal Life Support Organization, Extracorporeal Life Support Guidelines, Patient Care Practice Guidelines, https://www.elso.org/Resources/Guidelines.aspx.

[23] The Extracorporeal Life Support Organization: Extracorporeal Life Support Guidelines, Patient Care Practice Guidelines, https:/www.elso.org/Portals/0/IGD/Archive/FileManager/929122ae88cusersshyerdocumentselsoguidelinesgeneralalleclsversion1 3.pdf.

[24] D. Pujara, E. Sandoval, L. Simpson, H. R. Mallidi, and S. K. Singh, "The state of the art in extracorporeal membrane oxygenation," Seminars in Thoracic and Cardiovascular Surgery, vol. 27, no. 1, pp. 17-23, 2015.

[25] S. A. Conrad, L. R. Grier, L. K. Scott, R. Green, and M. Jordan, "Percutaneous cannulation for extracorporeal membrane oxygenation by intensivists: a retrospective single-institution case series," Critical Care Medicine, vol. 43, no. 5, pp. 1010-1015, 2015.

[26] Z. C. J. Higgs, D. A. L. Macafee, B. D. Braithwaite, and C. A. Maxwell-Armstrong, "The Seldinger technique: 50 Years on," The Lancet, vol. 366, no. 9494, pp. 1407-1409, 2005.

[27] S. C. Hendrickson and D. D. Glower, "A method for perfusion of the leg during cardiopulmonary bypass via femoral cannulation," The Annals of Thoracic Surgery, vol. 65, no. 6, pp. 1807$1808,1998$.

[28] W. Meredith, R. Rutledge, S. M. Fakhry, S. Emery, and S. Kromhout-Schiro, "The conundrum of the Glasgow Coma Scale in intubated patients: a linear regression prediction of the Glasgow verbal score from the Glasgow eye and motor scores," Journal of Trauma, vol. 44, no. 5, pp. 839-845, 1998.

[29] S. J. Han, H. S. Kim, K. Kim II et al., "Use of nafamostat mesilate as an anticoagulant during extracorporeal membrane oxygenation," Journal of Korean Medical Science, vol. 26, no. 7, pp. 945-950, 2011.

[30] S. Makino, M. Egi, H. Kita, Y. Miyatake, K. Kubota, and S. Mizobuchi, "Comparison of nafamostat mesilate and unfractionated heparin as anticoagulants during continuous renal replacement therapy," International Journal of Artificial Organs, vol. 39, no. 1, pp. 16-21, 2016.

[31] J.-H. Park, C. Her, H.-K. Min, D.-K. Kim, S.-H. Park, and H.-J. Jang, "Nafamostat mesilate as a regional anticoagulant in patients with bleeding complications during extracorporeal membrane oxygenation," International Journal of Artificial Organs, vol. 38, no. 11, pp. 595-599, 2015.

[32] J.-Y. Choi, Y.-J. Kang, H. M. Jang et al., "Nafamostat mesilate as an anticoagulant during continuous renal replacement therapy in patients with high bleeding risk a randomized clinical trial," Medicine (United States), vol. 94, no. 52, Article ID e2392, 2015.

[33] P. Safar, "Cerebral resuscitation after cardiac arrest: research initiatives and future directions," Annals of Emergency Medicine, vol. 22, no. 2, part 2, pp. 324-349, 1993.

[34] S. Aso, H. Matsui, K. Fushimi, and H. Yasunaga, "In-hospital mortality and successful weaning from venoarterial extracorporeal membrane oxygenation: analysis of 5,263 patients using 
a national inpatient database in Japan," Critical Care, vol. 20, no. 1, article 80, 2016.

[35] H. J. Yeo, W. H. Cho, and D. Kim, "Awake extracorporeal membrane oxygenation in patients with severe postoperative acute respiratory distress syndrome," Journal of Thoracic Disease, vol. 8, no. 1, pp. 37-42, 2016.

[36] F. Haneke, T. A. Schildhauer, A. D. Schlebes, J. T. Strauch, and J. Swol, "Infections and extracorporeal membrane oxygenation: incidence, therapy, and outcome," ASAIO Journal, vol. 62, no. 1, pp. 80-86, 2016.

[37] N. K. Kapur and D. C. Zisa, "Veno-arterial extracorporeal membrane oxygenation (VA-ECMO) fails to solve the haemodynamic support equation in cardiogenic shock," EuroIntervention, vol. 11, no. 12, pp. 1337-1339, 2016.

[38] M.-Y. Wu, P.-J. Lin, F.-C. Tsai, Y.-K. Haung, K.-S. Liu, and F.C. Tsai, "Impact of preexisting organ dysfunction on extracorporeal life support for non-postcardiotomy cardiopulmonary failure," Resuscitation, vol. 79, no. 1, pp. 54-60, 2008.

[39] C.-Y. Lin, F.-C. Tsai, Y.-C. Tian et al., "Evaluation of outcome scoring systems for patients on extracorporeal membrane oxygenation," The Annals of Thoracic Surgery, vol. 84, no. 4, pp. 1256-1262, 2007.

[40] C.-Y. Lin, Y.-C. Chen, F.-C. Tsai et al., "RIFLE classification is predictive of short-term prognosis in critically ill patients with acute renal failure supported by extracorporeal membrane oxygenation," Nephrology Dialysis Transplantation, vol. 21, no. 10, pp. 2867-2873, 2006.

[41] Y.-C. Chen, F.-C. Tsai, C.-H. Chang et al., "Prognosis of patients on extracorporeal membrane oxygenation: the impact of acute kidney injury on mortality," The Annals of Thoracic Surgery, vol. 91, no. 1, pp. 137-142, 2011.

[42] A. Babaev, P. D. Frederick, D. J. Pasta, N. Every, T. Sichrovsky, and J. S. Hochman, "Trends in management and outcomes of patients with acute myocardial infarction complicated by cardiogenic shock," Journal of the American Medical Association, vol. 294, no. 4, pp. 448-454, 2005.

[43] L. W. Klein, R. E. Shaw, R. J. Krone et al., "Mortality after emergent percutaneous coronary intervention in cardiogenic shock secondary to acute myocardial infarction and usefulness of a mortality prediction model," The American Journal of Cardiology, vol. 96, no. 1, pp. 35-41, 2005.

[44] L. A. Sleeper, H. R. Reynolds, H. D. White, J. G. Webb, V. Džavík, and J. S. Hochman, "A severity scoring system for risk assessment of patients with cardiogenic shock: a report from the SHOCK Trial and Registry," American Heart Journal, vol. 160, no. 3, pp. 443-450, 2010.

[45] U. Zeymer, A. Vogt, R. Zahn et al., "ArbeitsgemeinschaftLeitendeKardiologischeKrankenhausärzte (ALKK, Predictors of in-hospital mortality in 1333 patients with acute myocardial infarction complicated by cardiogenic shock treated with primary percutaneous coronary intervention (PCI); Results of the primary PCI registry of the ArbeitsgemeinschaftLeitendeKardiologischeKrankenhausärzte (ALKK)," European Heart Journal, vol. 25 , no. 4, pp. 322-328, 2004.

[46] J.-J. Sheu, T.-H. Tsai, F.-Y. Lee et al., "Early extracorporeal membrane oxygenator-assisted primary percutaneous coronary intervention improved 30-day clinical outcomes in patients with ST-segment elevation myocardial infarction complicated with profound cardiogenic shock," Critical Care Medicine, vol. 38, no. 9, pp. 1810-1817, 2010.

[47] M. Schmidt, A. Burrell, L. Roberts et al., "Predicting survival after ECMO for refractory cardiogenic shock: the survival after
veno-arterial-ECMO (SAVE)-score," European Heart Journal, vol. 36, no. 33, pp. 2246-2256, 2015.

[48] N. Doll, B. Kiaii, M. Borger et al., "Five-year results of 219 consecutive patients treated with extracorporeal membrane oxygenation for refractory postoperative cardiogenic shock," Annals of Thoracic Surgery, vol. 77, no. 1, pp. 151-157, 2004.

[49] H. Kim, S.-H. Lim, J. Hong et al., "Efficacy of veno-arterial extracorporeal membrane oxygenation in acute myocardial infarction with cardiogenic shock," Resuscitation, vol. 83, no. 8, pp. 971-975, 2012.

[50] E. C. Meltzer, N. S. Ivascu, C. A. Acres et al., "Extracorporeal membrane oxygenation in adults: a brief review and ethical considerations for nonspecialist health providers and hospitalists," Journal of Hospital Medicine, vol. 9, no. 12, pp. 808-813, 2014.

[51] M. Schmidt, M. Bailey, J. Sheldrake et al., "Predicting survival after extracorporeal membrane oxygenation for severe acute respiratory failure. The Respiratory Extracorporeal Membrane Oxygenation Survival Prediction (RESP) score," American Journal of Respiratory and Critical Care Medicine, vol. 189, no. 11, pp. 1374-1382, 2014.

[52] M. Schmidt, E. Zogheib, H. Rozé et al., "The PRESERVE mortality risk score and analysis of long-term outcomes after extracorporeal membrane oxygenation for severe acute respiratory distress syndrome," Intensive Care Medicine, vol. 39, no. 10, pp. 1704-1713, 2013.

[53] S. Klinzing, U. Wenger, P. Steiger et al., "External validation of scores proposed for estimation of survival probability of patients with severe adult respiratory distress syndrome undergoing extracorporeal membrane oxygenation therapy: A Retrospective Study," Critical Care, vol. 19, no. 1, article 142, 2015.

[54] F. Pappalardo, M. Pieri, T. Greco et al., "Predicting mortality risk in patients undergoing venovenous ECMO for ARDS due to influenza A (H1N1) pneumonia: The ECMOnet score," Intensive Care Medicine, vol. 39, no. 2, pp. 275-281, 2013.

[55] A. J. Rastan, A. Dege, M. Mohr et al., "Early and late outcomes of 517 consecutive adult patients treated with extracorporeal membrane oxygenation for refractory postcardiotomy cardiogenic shock," The Journal of Thoracic and Cardiovascular Surgery, vol. 139, no. 2, pp. 302-311.e1, 2010.

[56] E. A. J. Hoste, G. Clermont, A. Kersten et al., "RIFLE criteria for acute kidney injury are associated with hospital mortality in critically ill patients: A Cohort Analysis," Critical Care, vol. 10, no. 3, article R73, 2006.

[57] G. Mariscalco, R. Lorusso, C. Dominici, A. Renzulli, and A. Sala, "Acute kidney injury: a relevant complication after cardiac surgery," The Annals of Thoracic Surgery, vol. 92, no. 4, pp. 15391547, 2011.

[58] P.-S. Hsu, J.-L. Chen, G.-J. Hong et al., "Extracorporeal membrane oxygenation for refractory cardiogenic shock after cardiac surgery: predictors of early mortality and outcome from 51 adult patients," European Journal of Cardio-thoracic Surgery, vol. 37, no. 2, pp. 328-333, 2010.

[59] F. Formica, L. Avalli, L. Colagrande et al., "Extracorporeal membrane oxygenation to support adult patients with cardiac failure: predictive factors of 30-day mortality," Interactive Cardiovascular and Thoracic Surgery, vol. 10, no. 5, pp. 721-726, 2010.

[60] A. Loforte, A. Montalto, F. Ranocchi et al., "Peripheral extracorporeal membrane oxygenation system as salvage treatment of patients with refractory cardiogenic shock: preliminary outcome evaluation," Artificial Organs, vol. 36, no. 3, pp. E53E61, 2012. 
[61] M. Metra, S. Nodari, G. Parrinello et al., "Worsening renal function in patients hospitalised for acute heart failure: clinical implications and prognostic significance," European Journal of Heart Failure, vol. 10, no. 2, pp. 188-195, 2008.

[62] R. H. Mehta, J. D. Grab, S. M. O’Brien et al., "Bedside tool for predicting the risk of postoperative dialysis in patients undergoing cardiac surgery," Circulation, vol. 114, no. 21, pp. 2208-2216, 2006.

[63] R. W. Schrier and W. T. Abraham, "Hormones and hemodynamics in heart failure," The New England Journal of Medicine, vol. 341, no. 8, pp. 577-585, 1999.

[64] M. A. Cadnapaphornchai, A. K. Gurevich, H. D. Weinberger, and R. W. Schrier, "Pathophysiology of sodium and water retention in heart failure," Cardiology, vol. 96, no. 3-4, pp. 122131, 2001.

[65] A. Roch, S. Hraiech, E. Masson et al., "Outcome of acute respiratory distress syndrome patients treated with extracorporeal membrane oxygenation and brought to a referral center," Intensive Care Medicine, vol. 40, no. 1, pp. 74-83, 2014.

[66] W. C. Chen, K. Y. Huang, C. W. Yao et al., "The modified SAVE score: predicting survival using urgent veno-arterial extracorporeal membrane oxygenation within 24 hours of arrival at the emergency department," Critical Care, vol. 20, no. 1, article 336, 2016.

[67] G. Muller, E. Flecher, G. Lebreton et al., "The ENCOURAGE mortality risk score and analysis of long-term outcomes after VA-ECMO for acute myocardial infarction with cardiogenic shock," Intensive Care Medicine, vol. 42, no. 3, pp. 370-378, 2016.

[68] M. Kurusz and J. B. Zwischenberger, "Percutaneous cardiopulmonary bypass for cardiac emergencies," Perfusion, vol. 17, no. 4, pp. 269-277, 2002.

[69] G. Nichol, R. Karmy-Jones, C. Salerno, L. Cantore, and L. Becker, "Systematic review of percutaneous cardiopulmonary bypass for cardiac arrest or cardiogenic shock states," Resuscitation, vol. 70, no. 3, pp. 381-394, 2006.

[70] A. Roussel, N. Al-Attar, S. Alkhoder et al., "Outcomes of percutaneous femoral cannulation for venoarterial extracorporeal membrane oxygenation support," European Heart Journal: Acute Cardiovascular Care, vol. 1, no. 2, pp. 111-114, 2012.

[71] C. P. Schneider, M. G. Schwacha, and I. H. Chaudry, "Influence of gender and age on T-cell responses in a murine model of trauma-hemorrhage: differences between circulating and tissue-fixed cells," Journal of Applied Physiology, vol. 100, no. 3, pp. 826-833, 2006.

[72] S. R. Heckbert, N. B. Vedder, W. Hoffman et al., "Outcome after hemorrhagic shock in trauma patients," The Journal of Trauma, vol. 45 , no. 3, pp. 545-549, 1998.

[73] F. A. Moore, "Posttraumatic complications and changes in blood lymphocyte populations after multiple trauma," Critical Care Medicine, vol. 27, no. 4, pp. 674-675, 1999.

[74] F. A. Moore, A. Sauaia, E. E. Moore, J. B. Haenel, J. M. Burch, and D. C. Lezotte, "Postinjury multiple organ failure: a bimodal phenomenon," The Journal of Trauma, vol. 40, no. 4, pp. 501-512, 1996.

[75] J. A. Morris, E. J. Mackenzie, A. M. Damiano, and S. M. Bass, "Mortality in trauma patients: the interaction between host factors and severity," Journal of Trauma, vol. 30, no. 12, pp. 1476$1482,1990$.

[76] I. R. Turnbull, A. T. Clark, P. E. Stromberg et al., "Effects of aging on the immunopathologic response to sepsis," Critical Care Medicine, vol. 37, no. 3, pp. 1018-1023, 2009.
[77] K. E. Sands, D. W. Bates, P. N. Lanken et al., "Epidemiology of sepsis syndrome in 8 academic medical centers," Journal of the American Medical Association, vol. 278, no. 3, pp. 234-240, 1997.

[78] C.-E. Luyt, A. Landivier, P. Leprince et al., "Usefulness of cardiac biomarkers to predict cardiac recovery in patients on extracorporeal membrane oxygenation support for refractory cardiogenic shock," Journal of Critical Care, vol. 27, no. 5, pp. 524.e7-524.el4, 2012. 


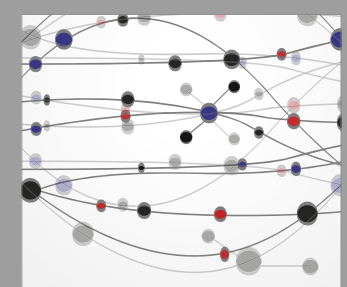

The Scientific World Journal
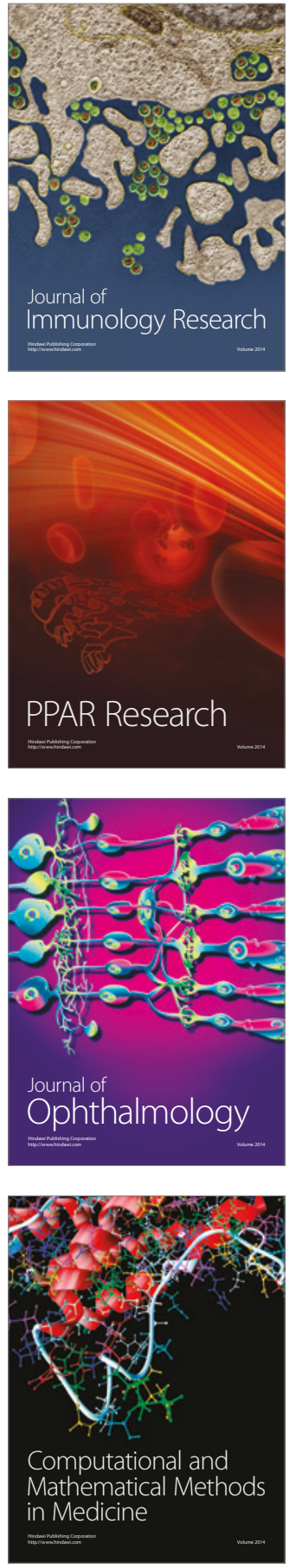

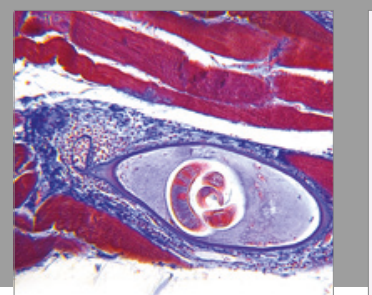

Gastroenterology Research and Practice
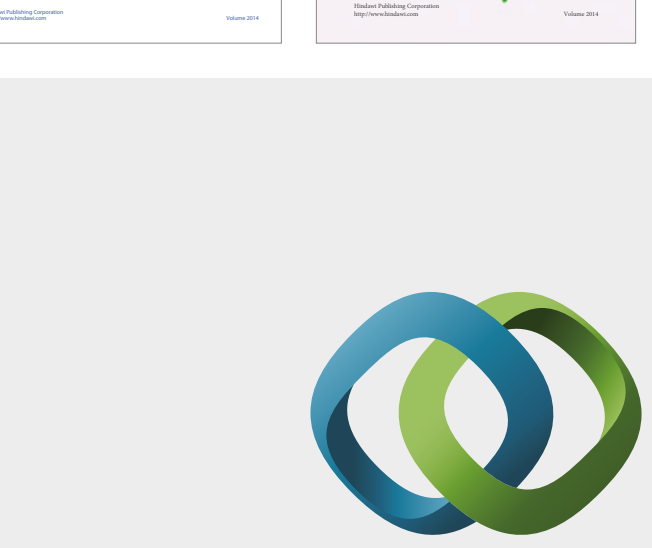

\section{Hindawi}

Submit your manuscripts at

https://www.hindawi.com
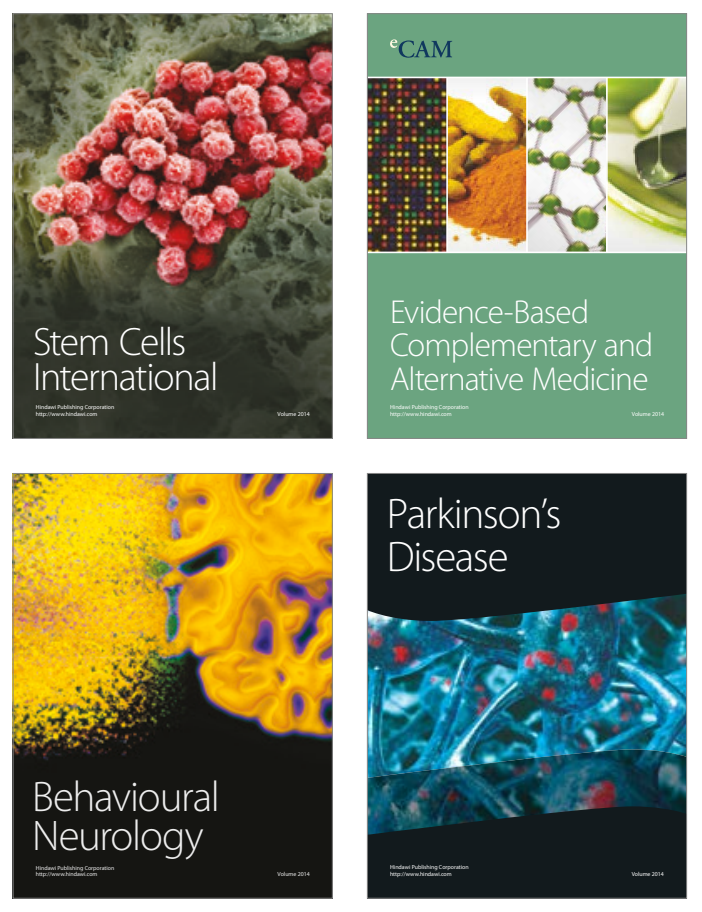
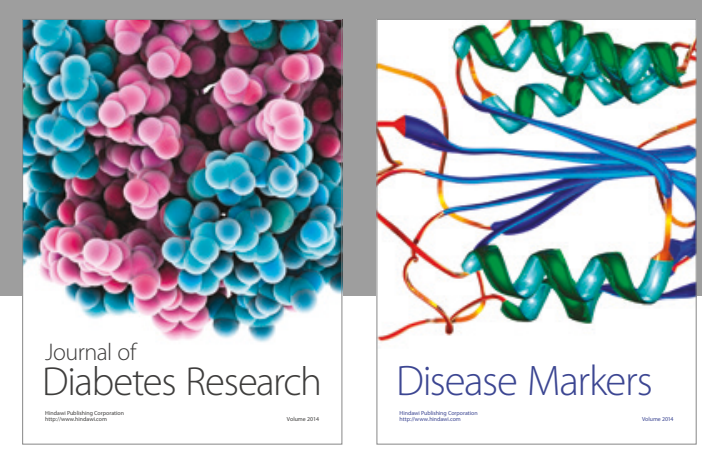

Disease Markers
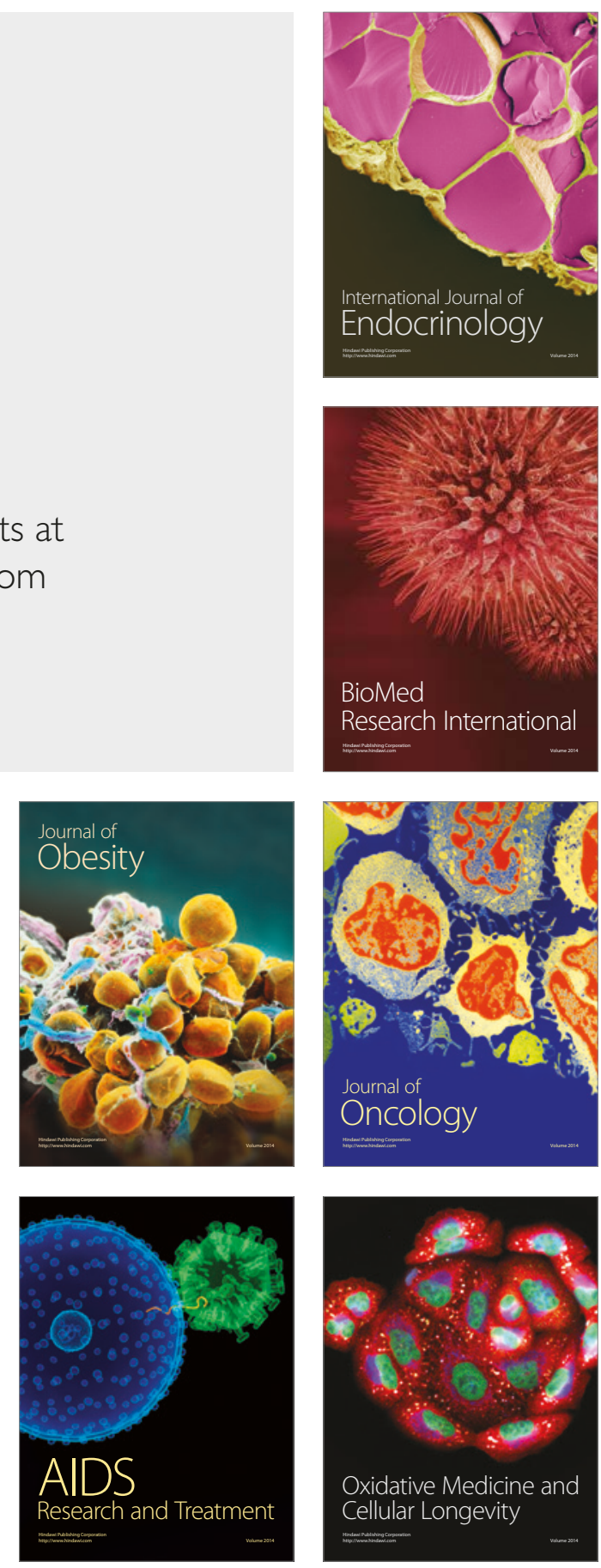